\title{
Kosteuden seuranta maassa uudella tekniikalla
}

\author{
Eemeli Linna
}

MTT, Pohjois-Pohjanmaan tutkimusasema, Tutkimusasemantie 15, 92400 Ruukki, eemeli.linna@mtt.fi

\section{Johdanto}

Jotta kasvien kasvu ja ravinteiden hyväksikäyttö turvataan, maassa on oltava riittävästi kosteutta. Maan kosteutta seurataan kosteudenseurantalaitteistolla ja sillä määritetään ensisijaisesti kastelutarve. Lisäksi kosteudenseuranlaitteistolla tarkastellaan maan hydraulista johtokykyä ja kasvien vedenottoa. Kosteudenseurantalaitteisto auttaa ymmärtämään maan kosteusolosuhteita ja veden liikkeitä.

Esitelmässä käytetty maan kosteuden mittausdata on MMM:n rahoituksella vuonna 2000 toteutetusta Perunan tihkukastelu - kalsiumlannoitustutkimuksesta. Maan kosteuden seurattiin Diviner 2000 ja Enviroscan -järjestelmillä, ja tutkimuksessa verrattiin tihkukasteltua ja kastelematonta koelohkoa toisiinsa.

\section{Aineisto ja menetelmät}

Tihkukastelu - lannoituskoe toteutettiin kenttäkokeena Pyhäjoella. Kosteuden seurantaa varten koelohkolle kairattiin reikiä mittauslaitteistolle ja jokaiseen reikään upotettiin muoviputki. Laitteet mittaavat maan kapasitiivisia ominaisuuksia noin 100 Mhz:n taajuudella muoviputken seinämän läpi. Saadut raakalukemat muutetaan regressiomallin avulla kosteuspitoisuuksiksi. Valmistaja on omien tietojensa mukaan tehnyt mallin osittain laboratorio-olosuhteissa ja osittain kenttäkokeilla. Mittaustuloksena saadaan kosteus tilavuuspitoisuusprosentteina maasta. Laitteiden absoluuttista tarkkuutta ei testattu.

Kokeen maalaji oli karkea hieta. Sen lakastumisraja on noin $7 \%$ vettä maatilavuudesta (Rowell 1996). Pääsääntöisesti kastelu aloitettiin kosteuspitoisuuden ollessa $12 \%$ maatilavuudesta. Teoriassa kastelu aloitetaan, kun kosteus on $65 \%$ kenttäkapasiteetista, eli kosteuspitoisuuksina $12-14 \%$ maatilavuudesta. (Potato Association of America Handbook 2001). Kasveille käyttökelpoisen veden sitomiskyky on karkealla hiedalla noin $12-14 \%$ (Rowell 1996).

Kenttäkokeen pääruudut olivat tihkukastelu ja kastelematon. Lannoitusmenetelmät olivat osaruutuina. Koelohko oli osana isompaa noin 2,5 hehtaarin tihkukastelussa olevaa lohkoa. Tässä yhteydessä tarkastellaan ainoastaan kosteuden seurantaan ja vesitalouteen liittyviä tuloksia. Tulokset eivät ole ilman lisätutkimuksia sovellettavissa muille maalajeille.

\section{Tulokset ja tulosten tarkastelu}

\section{Kosteuden muutokset kastellulla ja kastelemattomalla lohkolla kasvukauden aikana}

Kastelemattoman lohkon kosteuspitoisuus laski 10 - $40 \mathrm{~cm}$ :n kerroksissa elokuun puoleen väliin saakka (kuva 1), mihin saakka myös luontainen sadanta oli vähäistä. Sen jälkeen sateiden vaikutuksesta maan kosteuspitoisuus pysyi korkealla kasvukauden loppuun.

Kastelematon lohko kärsi jonkinasteisesta kuivuusstressistä elokuun alkupuolella (kuva 1). Perunalla maan kosteuspitoisuus ei saisi laskea alle $65 \%$ kenttäkapasiteetista (Potato Association of America Handbook 2001). Kosteuspitoisuus laski $65 \%$ :n alapuolelle lähtökosteudesta, joka oli jo mittausten alkaessa kenttäkapasiteetin alapuolella. Kasvukauden lopulla kosteuspitoisuudet olivat huomattavasti alkukesän lukemia korkeammat.

Kastellulla lohkolla kosteuspitoisuudet olivat suhteellisen korkeat koko kasvukauden ajan (kuva 2). Mittausanturi sijaitsi keskellä penkkiä ja tihkuletku oli antureiden vieressä. Kasteluvesi valui tihkuletkusta antureiden mittausalueelle, mikä nosti kosteuslukemia kastelun vaikutuksesta hetkellisesti korkealle. Kosteuspitoisuus pysyi kastelun vaikutuksesta huomattavasti korkeammalla lähtö- ja loppukosteuteen sekä kastelemattomaan lohkoon verrattuna.

Käsinmittauksessa putken 12 kosteuslukemat olivat mittausten alkaessa muita mittauspisteitä huomattavasti matalampia (kuva 3). Lukemat kuitenkin nousivat kasvukauden aikana kaventaen eroa muihin mittauspisteisiin. On mahdollista, että mittausputken ja maan välissä oli ilmatilaa, joka hitaasti täyttyi kasvukauden edetessä. Poikkeavasta lähtökosteudesta huolimatta kosteuden muutokset olivat kasvukauden aikana loogisia. 


\section{Maan hydraulinen johtavuus, veden liike ja kasvien vedenoton tarkastelu}

Kastelun vaikutuksesta pintakerrosten kosteuspitoisuus oli korkeampi ja lisäveden sitomiskyky heikompi kuin kastelemattomalla lohkolla (kuva 4). Elokuun 15. päivä satoi $32 \mathrm{~mm}$. Sateen vaikutuksesta kosteuslukemat nousivat kastellulla lohkolla järjestelmällisesti kaikilla syvyyksillä (kuva 2). Pintakerrokset pidättivät osan sadevedestä, mikä hiukan vaimensi sateen vaikutusta syvemmissä maakerroksissa.

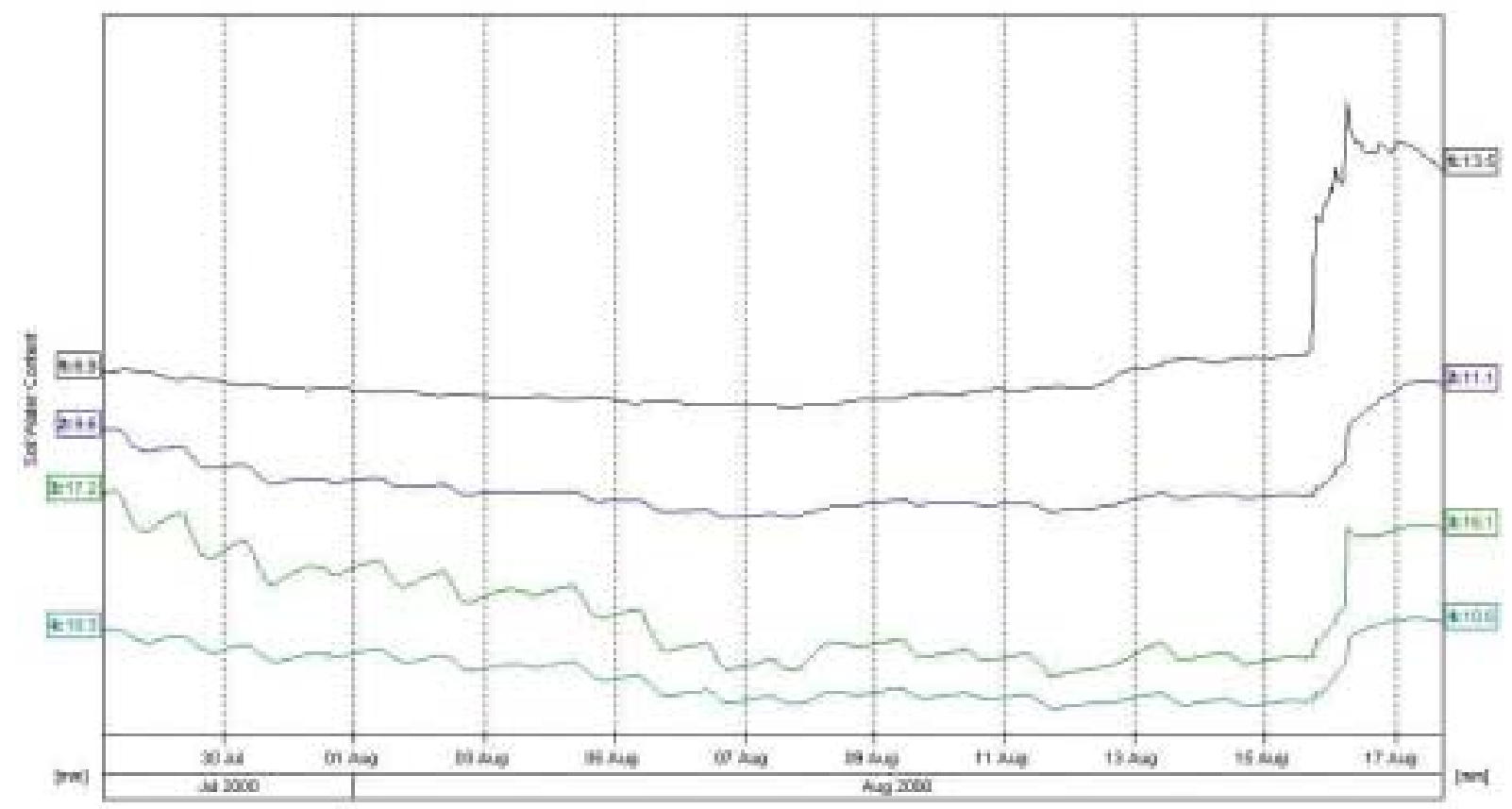

Kuva 1. Kastelemattoman lohkon kosteuslukemat ajan suhteen. Käyrät on sijoitettu kuvaajaan mittaussyvyyden mukaiseen järjestykseen. Jokainen käyrä vastaa yhtä mittaussyvyyttä. Järjestys ylhäältä alaspäin: 10, 20, 30 ja $40 \mathrm{~cm}$. Jokaista mittaussyvyyttä vastaavat kosteuspitoisuudet on ilmoitettu millimetreinä kuvaajan molemmin puolin.

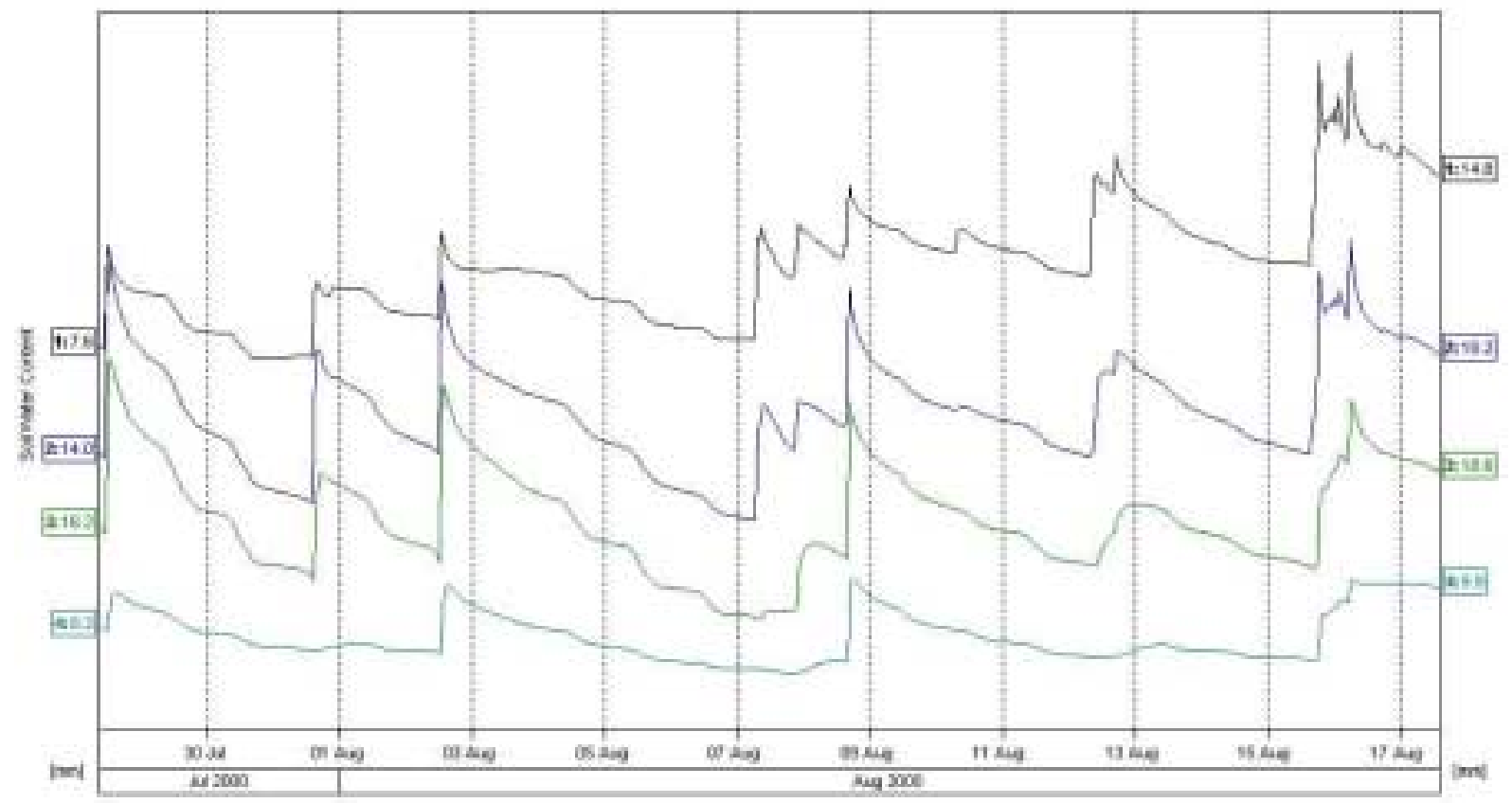

Kuva 2. Tihkukastellun lohkon kosteuslukemat ajan suhteen. Käyrät on sijoitettu kuvaajaan mittaussyvyyden mukaiseen järjestykseen. Jokainen käyrä vastaa yhtä mittaussyvyyttä. Järjestys ylhäältä alaspäin: 10, 20, 30 ja $40 \mathrm{~cm}$. Jokaista mittaussyvyyttä vastaavat kosteuspitoisuudet on ilmoitettu millimetreinä kuvaajan molemmin puolin.

Kastelemattomalla lohkolla maan pintakerrokset pidättivät sadevettä huomattavasti suuremman määrän kasteltuun verrattuna (kuva 1). Syvemmissä maakerroksissa kosteuslukemat nousivat kasteltua myöhemmin ja muutokset olivat pienempiä. Lisäksi kastelemattomalla lohkolla osa sadevedestä virtasi 
penkin pintaa pitkin, mikä näkyy elokuun 16. päivä äkillisenä kosteuden nousuna $30 \mathrm{~cm}: n$ syvyydessä. Sama ilmiö esiintyi erään heinäkuun ukkoskuuron jälkeen, jolloin vettä satoi 5 - 8 mm lyhyessä ajassa. Vesi jakautui kasteltuun maahan tasaisesti eri syvyyksille, mutta kuivassa penkissä kosteuden selvä nousu havaittiin vain $30 \mathrm{~cm}: n$ syvyydessä. Vesi virtasi kuivan penkin pintaa pitkin vakoon ja imeytyi sieltä maahan myöhemmin (kuva 4). Kastellun maan hydraulinen johtavuus on huomattavasti kastelematonta parempi (Rowell 1996).

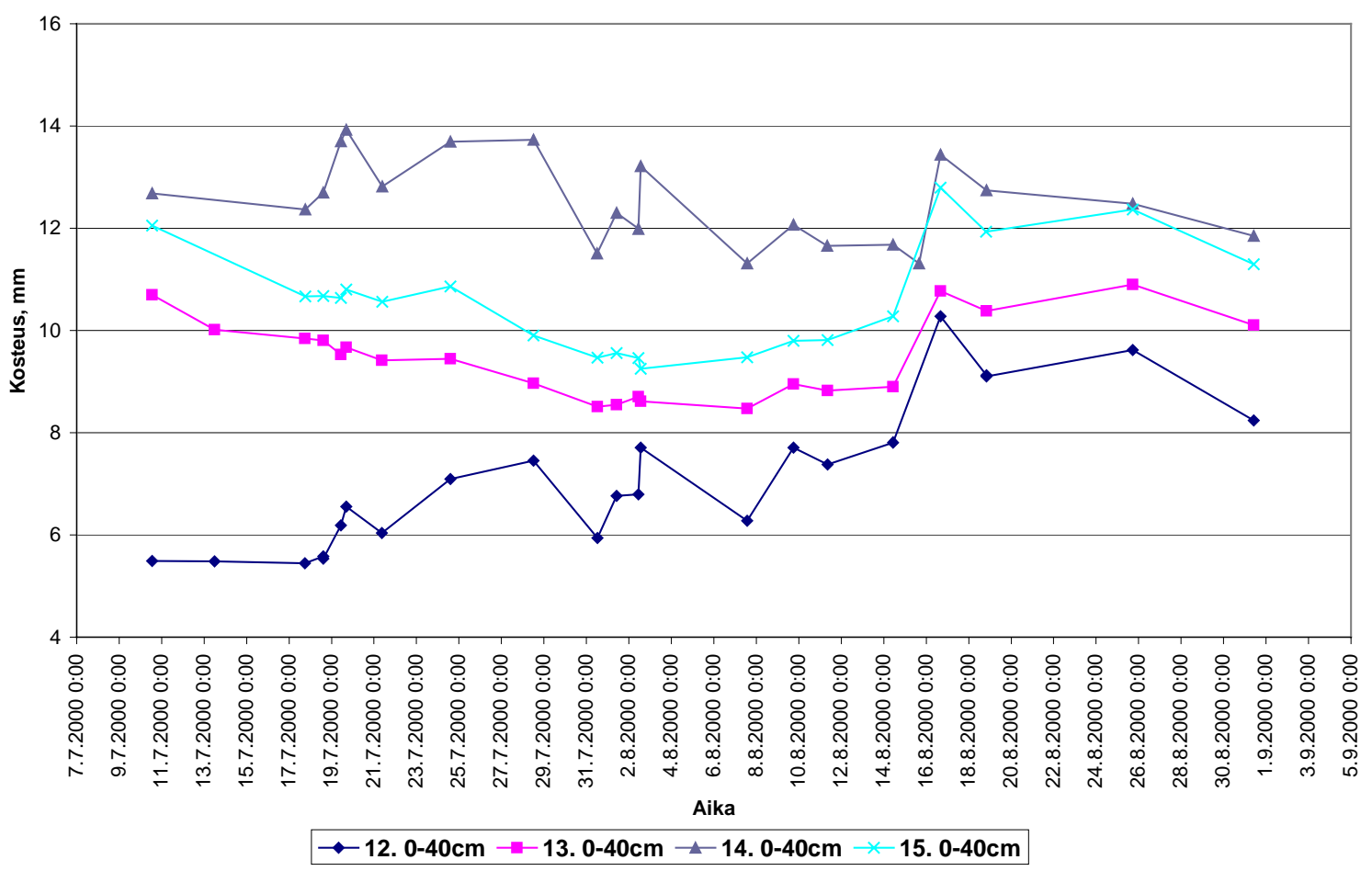

Kuva 3. Käsin mitattujen kosteuslukemien keskiarvokäyrät neljästä mittauspisteestä ajan suhteen. 12 ja 14 ovat tihkukastellulta lohkolta ja 13 ja 15 ovat kastelemattomalta lohkolta. Kaikki käyrien pisteet ovat neljän mittaussyvyyden keskiarvoja. Mittaussyvyydet ovat 10, 20, 30 ja $40 \mathrm{~cm}$.

Käsinmittauksen mukaan elokuun puolivälissä sateiden vaikutus nähdään $50-70 \mathrm{~cm}: n$ kerroksissa selvemmin kastellulla kuin kastelemattomalla lohkolla. Kastellun maan pintakerrosten lisäveden sitomiskyky oli kastelematonta heikompi ja siitä syystä $50-70 \mathrm{~cm}: n$ kerrokseen valunut vesimäärä oli suurempi. Tämä tukee jatkuvan seurannan tuloksia.

Sateen ja kastelun lisäksi kosteuspitoisuuksia muuttavia tekijöitä maassa ovat gravitaation aiheuttama valunta, kosteuserojen tasoittuminen, evaporaatio ja kasvien vedenotto. Kosteuserojen tasoittuminen sisältää kapillaarisen vedennousun. Evaporaatio on suurimmillaan pinnassa ja juurten vedenotto $20-40 \mathrm{~cm}$ syvyydellä. Kokeessa kasvien vedenotto oli voimakkainta $30 \mathrm{~cm}: n$ syvyydessä kastelusta riippumatta (kuvat 1 ja 2).

Kosteuskäyrät laskevat päiväsaikaan jyrkästi kasvien vedenoton ja evaporaation vaikutuksesta kastelusta riippumatta (kuvat 1 ja 2). Öisin mittauslukemat laskevat kastellulla ja nousevat kastelemattomalla lohkolla. Kosteuslukemat muuttuvat öisin pääasiassa vain kosteuserojen tasoittumisen vaikutuksesta. Kastellulla lohkolla vesi liikkuu poispäin penkin keskiosasta ja kastelemattomalla penkin keskiosaan päin (kuva 4). Evaporaation osuutta on mahdoton päätellä kosteudenseurannan perusteella.

Kasvien vedenottoa voidaan karkeasti vertailla jatkuvan seurannan mittaustulosten perusteella, jos valitaan ajanjakso, jolloin ei sada eikä ole kastelua. Laskentatapa olettaa, että maassa tapahtuva veden liike on vakio ympäri vuorokauden ja lisäksi kasvien vedenottoa ja evaporaatiota tapahtuu vain päivisin. Kasvien vedenotto ja evaporaatio lasketaan erilleen vähentämällä öisestä kosteuden muutosnopeudesta päivittäinen kosteuden muutosnopeus $(\mathrm{mm} / \mathrm{h})$. Evaporaation osuus on kasvien vedenottoon verrattuna pieni, koska vertailussa on mukana mittaussyvyydet $40 \mathrm{~cm}$ :iin saakka.

Näin laskettuna kasvien vedenotto ja evaporaatio oli voimakkaampaa kastellulla kuin kastelemattomalla lohkolla heinäkuun lopussa ja elokuun alkupuolella. Elokuun viimeisinä päivinä kastelemattoman lohkon vedenotto oli kuitenkin huomattavasti kasteltua voimakkaampaa. Elokuun kuivuus hidasti mahdollisesti ravinteiden hyväksikäyttöä, mikä näkyi myöhäisenä vedenottona kastelematto- 
malla lohkolla. Satotulokset tukevat tätä perustelua (Forsman \& Virtanen 2000). Menetelmässä kuitenkin tehdään karkeita yleistyksiä. Menetelmä pitäisi todentaa useilla mittauspisteellä, jatkuvilla kasvustohavainnoilla ja sääasemalla, joka mittaa haihdunnan lohkoittain.

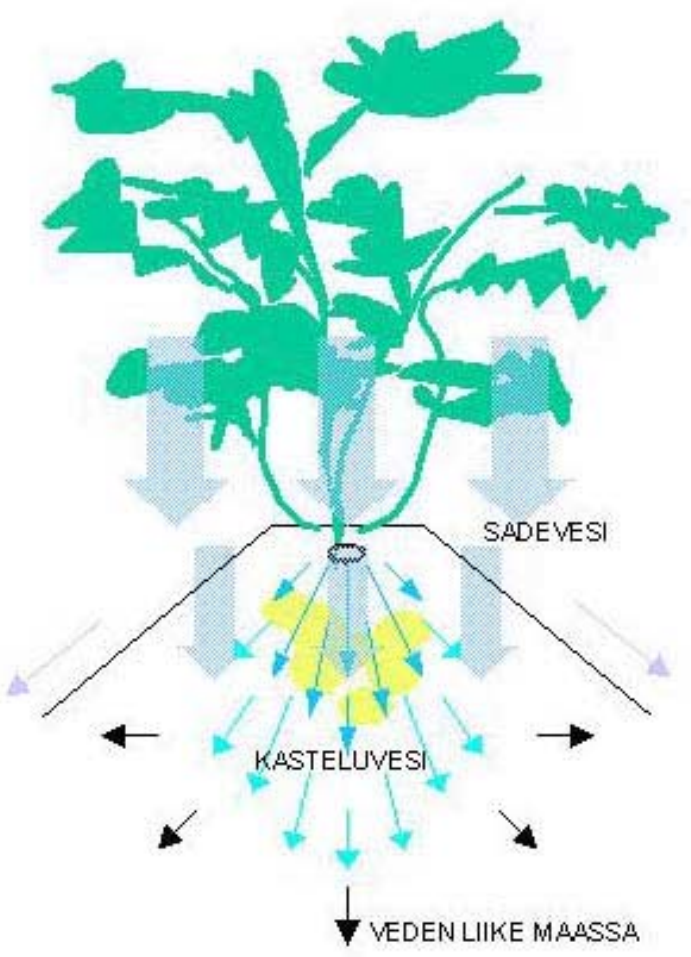

Tihkukasteltu

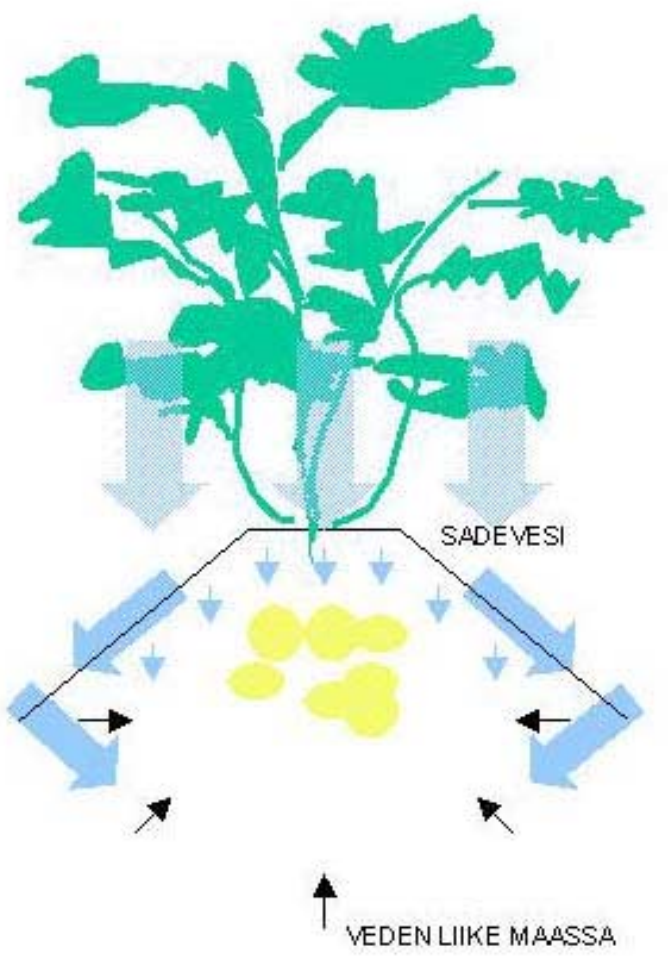

Kuiva

Kuva 4. Kosteuserojen aiheuttama veden liike ja sadeveden imeytyminen karkealla hiedalla kastellulla ja kuivuudesta kärsivällä lohkolla. Tihkukastellussa penkissä on kasteluletku penkin yläosassa ja kasteluvesi on merkitty pienillä vaaleansinisillä nuolilla. Perunat on merkitty keltaisella. Kuvassa ei ole juuristoa.

\section{Johtopäätökset}

Kastelematon lohko kärsi todennäköisesti kasvukauden aikana jonkinasteisesta vedenpuutteesta elokuun alkupuolella. Tätä puoltaa maan runsas kuivuminen, heikompi vedenotto ja pienempi kasvunoston ja lopullisen noston sato (Forsman \& Virtanen 2000). Vedenotto oli voimakkainta $30 \mathrm{~cm}: n$ syvyydellä. Tihkukastelu näytti pitävän kosteutta yllä enimmäkseen juuristovyöhykkeessä. Kastelun vaikutuksesta syvälle huuhtoutuneet vesimäärät olivat vähäisiä. Sateet todistivat koelohkon maalajilla sen, että penkin perusteellisen kuivumisen jälkeen hydraulinen johtokyky on heikko. Päältäkastelua käytettäessä vesi on annosteltava pienissä erissä, jotta se imeytyisi tehokkaasti penkkiin.

Laitteiden absoluuttisesta tarkkuudesta ei ole riittävästi tietoa. Kosteudenseurannan tuloksia voidaan kuitenkin tulkita tällä tarkkuudella sekä kasvukauden aikana tapahtuvien kosteuden muutosten perusteella riittävästi, jotta kastelutarve voidaan määrittää. Kosteudenseurantamenetelmillä voidaan välttää liikakastelu ja mahdolliset ravinnehuuhtoumat.

\section{Kirjallisuus}

Forsman, K., Virtanen, E. 2000. Perunan tihkukastelu -hanke. Tutkimusraportti 2000. Biologiaosio. Maa- ja metsätalousministeriö. Perunan tihkukasteluhanke. $55 \mathrm{~s}$.

Linna, E. 2000. Perunan tihkukastelu -hanke. Tutkimusraportti 2000. Vesitalous- ja teknologiaosio. Maa- ja metsätalousministeriö. Perunan tihkukasteluhanke. $55 \mathrm{~s}$.

Linna, E. 2001. Tihkukastelu perunalle. Laitteiston toiminta, käyttö ja vesitalous. Kandidaatintutkielma. 37 s.

Potato Association of America Handbook. 2001. Saatavilla www-muodossa: URL: <http://www.css.orst.edu/Classes/CSS322/Growing.htm>. 27.4.2001.

Rowell, D. L. 1994. Soil science: Methods and applications. Department of Soil Science, University of Reading. Reprinted 1995, 1996. Addison Wesley Longman Limited. 350 p. 